
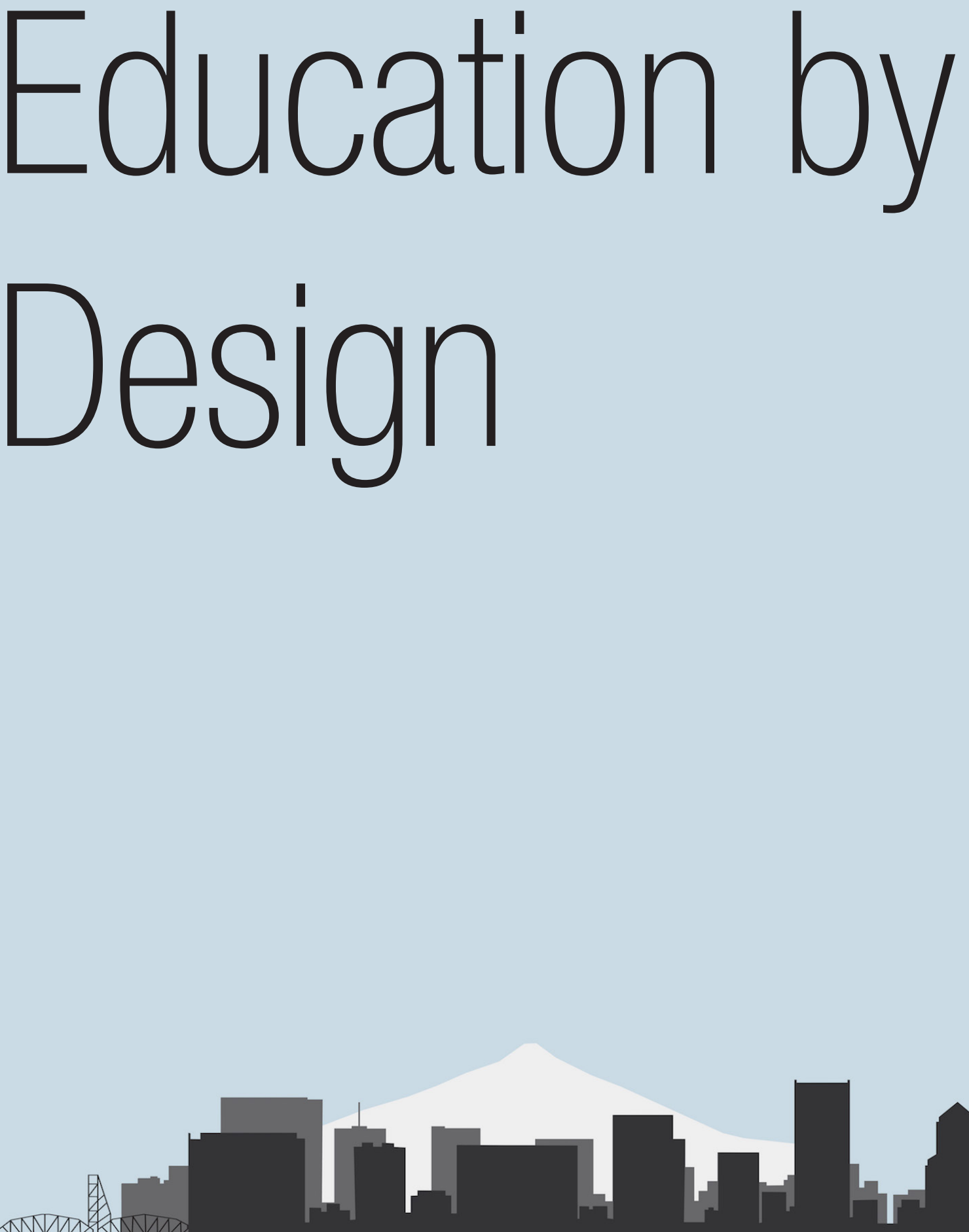

2019 Reynolds Symposium: Education by Design October 18-20, 2019 


\section{Organizing Committee:}

[co-organizers]

Professor Alison Kwok, Ph.D, FAIA, University of Oregon

Emeritus Professor John Reynolds, FAIA, University of Oregon

\section{[Symposium coordinator]}

Isabel Rivera, Ph.D., University of Oregon

Professor Walter Grondzik, P.E., Ball State University

Professor Bruce Haglund, AIA Assoc., University of Idaho

Assistant Professor Emily McGlohn, AIA, Auburn University

Associate Professor Ulrike Passe, lowa State University

Assistant Professor Siobhan Rockcastle, Ph.D., University of Oregon

Sharon Refvem, FAIA, LEED Fellow, Senior Associate and Director, Sustainability Resource Group, Hawley Peterson Snyder 


\title{
Comfort and Efficiency: Strategies to Develop a Climate Appropriate Affordable Home.
}

\author{
Emily M. McGlohn, AIA, NCARB, LEED AP \\ Assistant Professor \\ Auburn University \\ Newbern, Alabama \\ mcgloem@auburn.edu
}

\begin{abstract}
Alabama's Blackbelt counties suffer from some of the poorest economic conditions in the country. Thirtytwo percent of all people living there, live in poverty. Affordable and climate appropriate housing that contributes to the well-being of this significantly sized group is lacking, and the challenges are many. Auburn University's Rural Studio attempts to address this need through the 20K Home Project. This paper focuses on one aspect of this fourteen-year research project: the design strategies of a climate appropriate, affordable home and ways to teach students to prioritize options.

Within the larger 20K Home Project, third-year architecture students at Rural Studio build one house a year. They start with the plans of a previously designed home from the project. They inherit the strategies and details from another group of students. To understand the house, they analyze the conceptual and tangible aspects of the design. Learning how to prioritize and select from the ever-growing number of ways to structure, enclose, insulate, heat, and cool a home, while minding the climatic characteristics of hot-humid Alabama is the objective. Making informed adjustments to the existing strategies and building a house to test their selections is the goal. This paper is a case study of the 2017-18 Rural Studio third year project house and addresses the pedagogical approach for this process.
\end{abstract}

\section{INTRODUCTION}

Rural Studio is a fully immersive design-build program. Third-year and fifth-year architecture students move off main campus to gain hands-on experience designing and constructing projects to meet local community needs. In one academic year, two groups of third-year architecture students build one house as part of an on-going research project about affordable rural housing. This continuation of their education from main campus bolsters the students' comprehension of materials, light wood-frame construction, appropriate enclosure assemblies, and processes of construction management. It also offers an iterative research-based experience that allows students to participate in the fourteen-year 20K Home Project the Studio endeavors to develop as a way to provide a model for rural affordable housing to the region.

\section{The 20K Home Project}

In response to Alabama's great need for affordable, permanent housing options the $20 \mathrm{~K}$ Home Project developed out of necessity fourteen years ago. The project's main goal is the design of a beautiful, climate appropriate, efficient home that someone living below the national line of poverty can afford to purchase. Each year the Studio builds two homes and each one is slightly different. Each version studies a unique aspect of housing design, and over fourteen years many versions now exist.

Over twenty-five home models have been designed and built. Of these, three are the most suitable onebedroom options for further development as the Product Line Homes - Versions 8, 9, and 10. See figure 1. As Rural Studio continues to develop the 20K Home Project, research continues at several levels. Each year a group of fifth-year architecture students design and build a new model that addresses a particular research topic such as aging in place, alternative storage solutions, or overall improved energy efficiency. The third-year students build an iteration of the Product Line Homes. Their iteration incorporates 
solutions to problems they identify during an analysis of previously built homes with client feedback. Their efforts contribute to the body of knowledge Rural Studio is growing on durable, beautiful, and efficient construction details for affordable rural housing.

\section{Product Line Homes}

Versions 8, 9, and 10 are all one bedroom, stick frame buildings designed to be replacement housing for the large number of individuals who own property but live below the poverty line in the area. They are alternatives to the house trailer. In the future the plans, details, and construction specifications will be available to non-profit affordable housing developers who need a similar model for people in their service area looking to own a home. Version 10 is the model that students studied during the 2017-2018 academic year.

These houses use standard stick frame construction and code compliant performance standards. The most important goal of the $20 \mathrm{~K}$ Home Project is affordability balanced with energy efficiency, occupant health, beautiful design, and a sense of community. To accomplish this aspiration, most 20K Houses utilize a pier and girder foundation, 2x6 stud walls, trussed roof, vinyl widows, metal siding and roof, and fiberglass batt insulation. Figure 1 depicts the typical plan and section of $20 \mathrm{~K}$ v10 Joanne's Home, the Product Line Home selected for further development for the studio project described in this paper.
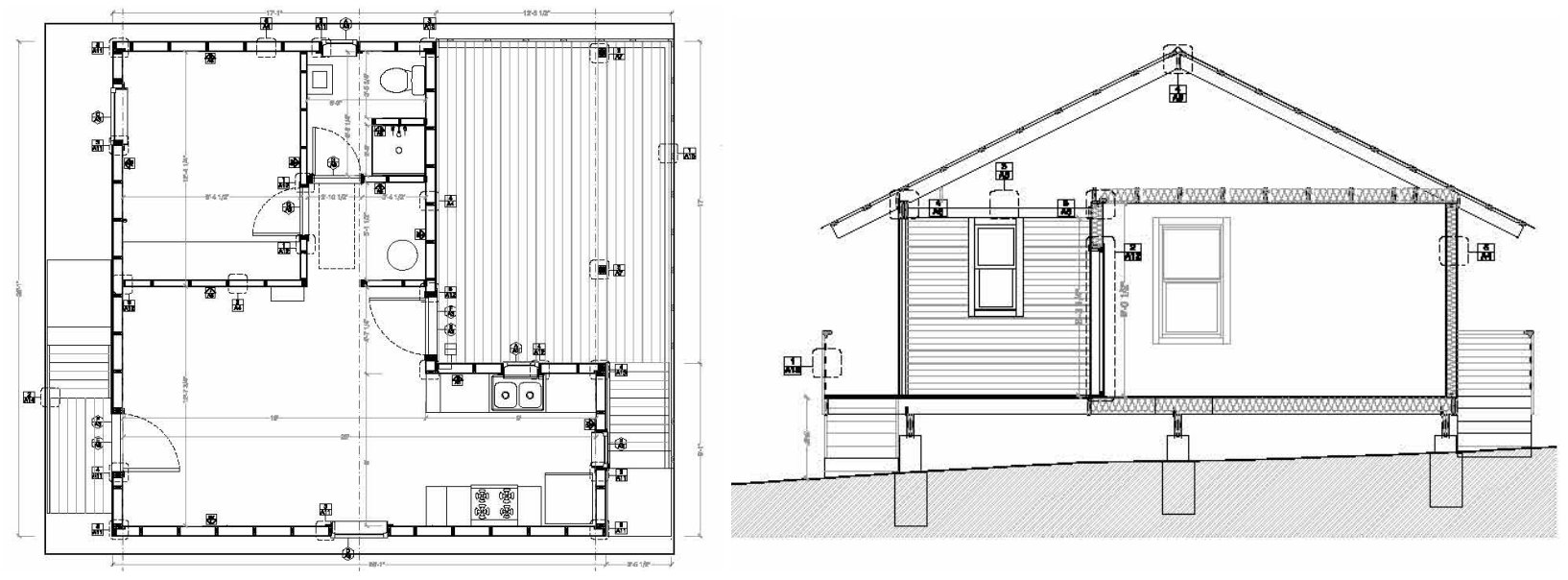

Fig. 1. 20K v10 Joanne's Home plan and section. NTS

\section{THIRD YEAR'S PURPOSE}

Third-year studio's task to help develop the Product Line Homes further by testing alternative structural systems, enclosure details, plan layouts, and porch to ground connections. The third-year studio design program introduces a new set of variables each year; the students refine the design using these variables through consensus building, and then build the altered design over the 9-month period. Subsequent classes then study the resulting project to further refine the details and construction strategies of the $20 \mathrm{~K}$ Home Project.

The research objectives of the third-year course of study are: Compare and analyze the built details and performance of the existing homes in the Product Line Houses, quickly test and improve alternative architectural details for the Product Line Homes as the third-year students build a new house every academic year, record and catalog alternative systems for future study at Rural Studio. This paper records the pedagogical goals, design process, and results of the 2017-18 project house. 


\section{Variables Studied}

The original Version 10 is $2 \times 6$ light wood-frame construction on a pier and girder foundation. The roof trusses are conventional trusses, and the home has no enclosed closets (with doors) for storage. Although there are numerous topics the third-year class could study, the students and faculty determined these variables were the most critical to improve in the new home through a systematic review of the Product Line Homes, her old home, and the client's needs. The reasons to study these topics are as follows:

Pier and girder platform framing places the house around thirty-eight inches above grade, making the inclusion of a ramp nearly impossible. The client requested a ramp, so an elevated slab provides a lower finish floor grade. Without an enclosure around the crawlspace insurance companies will not extend a policy. Past 20K homes are open and clients have to enclose the crawlspace themselves. An elevated slab provides increased energy efficiency improving the performance of the home and lowering utility bills.

The lack of closets is a conscious decision in the Product Line Homes. The houses include a flexible storage zone with a curtain, which saves the cost of doors and additional gypsum corners. This does not suit every individual. The floor plan of version 10 was adjusted to include two closets.

Conventional roof trusses compress insulation laid on the ceiling in a cold attic scenario. To increase energy efficiency the roof structure is made of heeled trusses so full depth insulation is possible at the perimeter of the attic.

\section{Pedagogical Purpose}

The pedagogical purpose of the third year design studio is to first, provide a hand-on construction experience to students. Second, the purpose is to engage the students in a methodical analysis of the site and the client's needs to determine which Product Line Home is most appropriate for construction. Third, the purpose is to contribute to the larger $20 \mathrm{~K}$ Home Project research by exploring alternative details, assemblies, and construction methods to advance previous efforts. In this last objective, there is room to test higher performing alternatives against the baseline standard established over the last fourteen years.

The students also study traditional issues of design, such as analyzing the client's lifestyle and how it overlapped with the features of each Product Line home to select the right one for her. Students determined where the client's new house would rest on the property. The relationship to her sister's home and solar orientation were critical components of the design studio. The students considered context, durability, energy efficiency, and client satisfaction in regards to the materials selected for the home.

Narrow design questions in this studio are strategic. To stay on schedule and complete the house by the end of April each year, quick yet thorough decisions are necessary. Small design questions allow students to fully engage the details of construction and complete the house. The detailed study of materials and methods also supports the third-year course of study, which follows required technical coursework taken back on main campus before moving to the Studio.

\section{Design Process}

Before redesign happens, students gather information about the Product Line Homes and the client's existing home to make informed group decisions. In groups, students study the construction documents, design intent, the performance, and the successes and weaknesses of the existing built versions. Students meticulously record the client's belongings and study her preferences. Beautiful, hand rendered elevations pay respect to trailer house she lovingly kept for forty-three years. See figure 2. All of this information feeds into the design process of the new home. 


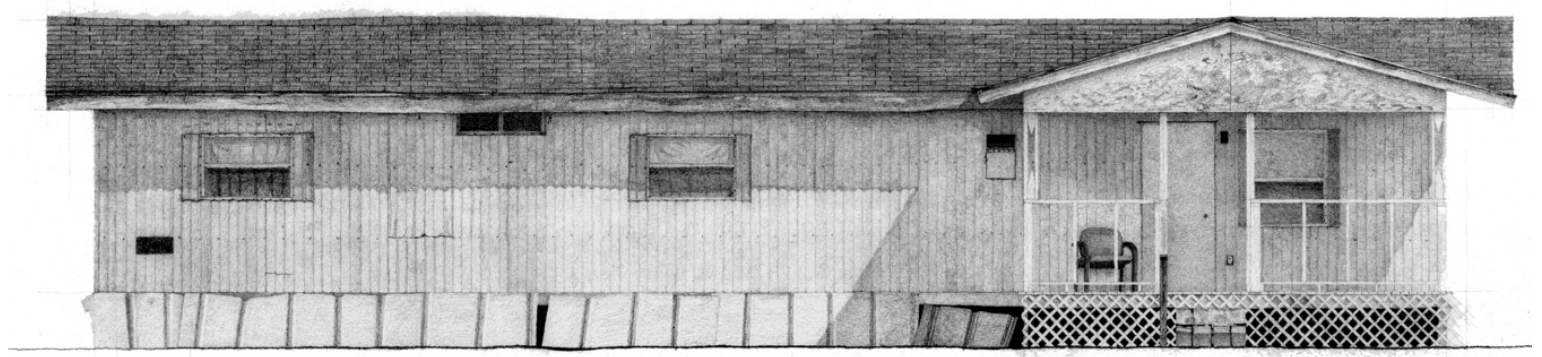

Fig 3. Rendered elevation of Mrs. Zee's house trailer by Will Hall.

\section{7-18 PROJECT HOUSE}

In the 2017-18 project house, Mrs. Zee's Home, several aspects of the Product Line Homes were studied: accessibility/foundation, storage capacity, roof construction, and flexible interior spaces. Students participate in an extensive diagraming and comparison process. This helps them become familiar with each home and information necessary to make the right decision for the client.

\section{Elevated Slab}

Typically, houses in the Home Project utilize a pier and girder system with dimensional lumber. This foundation system is flexible to site topography, touches the ground lightly, affordable, and constructed easily by students. Although effective, the disadvantages of this system warranted an investigation into alternative foundation systems that would increase durability, energy performance, and lower the house to grade so a ramp is possible. It was determined that an elevated slab is the best alternative and a worthwhile endeavor, as Rural Studio has never built with this common system in the past.
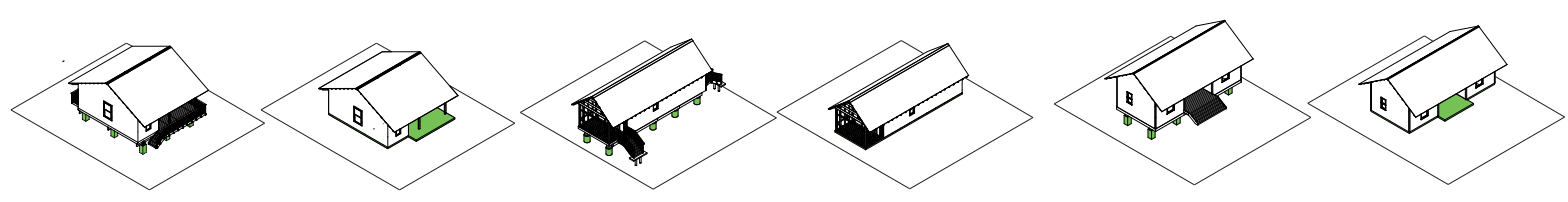

Fig 4. Pier vs. slab spatial porch studies by Will Hall.

On a concrete footing, a concrete masonry unit (CMU) perimeter wall outlines the footprint. Figure 5 shows the construction detail and the foundation backfilled with engineered soil, four inches of gravel, and a vapor barrier; a concrete slab rests on top. Better than a slab on grade and raised from the ground, Mrs. Zee's house offers distance from the muddy surroundings in the winter and a good vantage point from her porch in the summer. Students studied how different foundations effect the quality of the porch through diagram; see fig. 4 .

Successfully, this foundation demonstrated an alternative to the pier and girder system. Mrs. Zee's Home is sixteen inches from grade making it possible to incorporate a ramp into the front porch configuration. Mrs. Zee's house has a site-specific porch stair too. Her sister lives next door and quick access from one porch to the other was important. Figure 6 shows the wide stair to the south offers seating for family members and a short cut for her sister. Other groups at the Studio are already using the elevated slab in their designs and improving the details. Two new housing projects, where accessibility is a primary concern, are utilizing this system because of its proximity to the ground and performance longevity. 

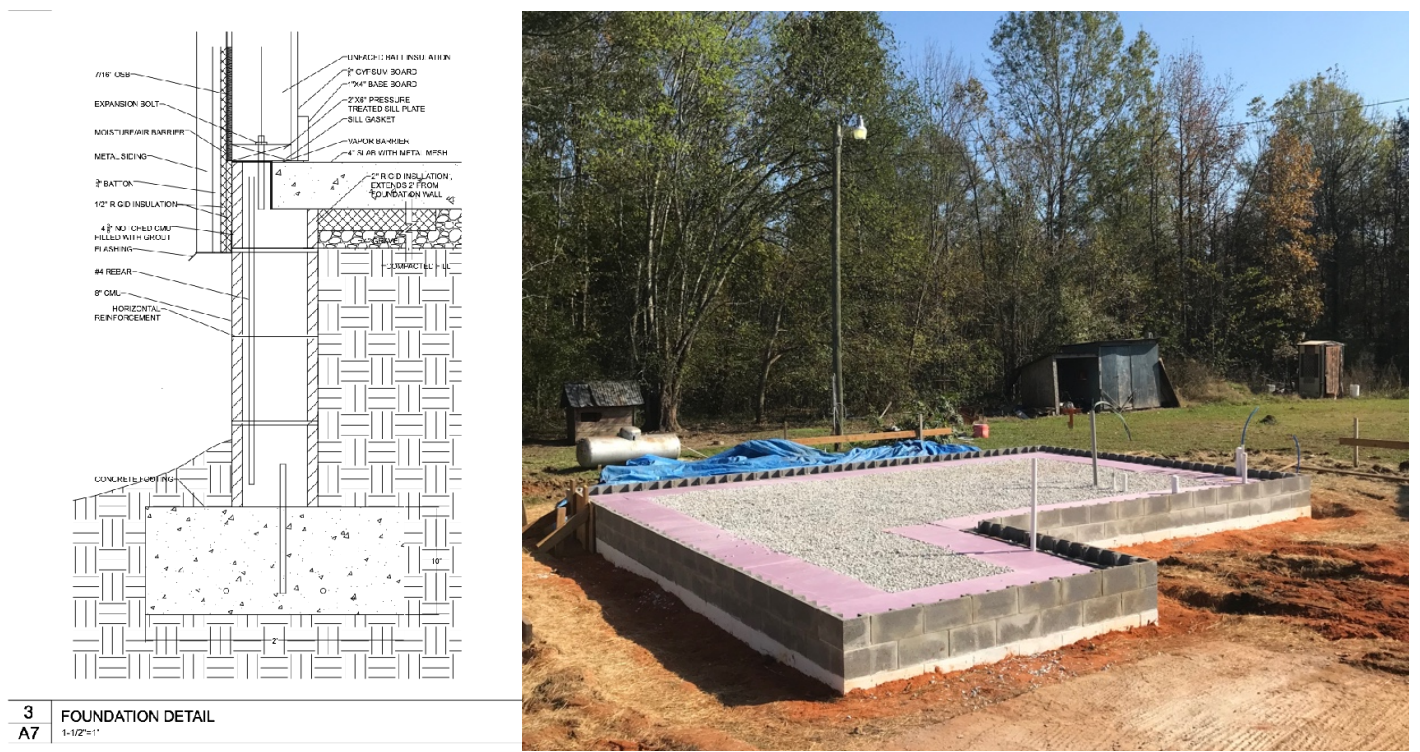

Fig 5. Elevated slab detail (NTS) and construction photo. Photo by Emily McGlohn

\section{Storage, Roof Construction, and Flexible Spaces}

At the request of Mrs. Zee, her house has closets. Normally simple storage zones that use a curtain to hide stored items come in the Product Line Homes. To test the feasibility of a traditional closet, students altered the floor plan to include a bedroom and utility closet. In part, this was possible due to an increase in footprint size that corresponds to block coursing dimensions.

Although a seemingly simple exercise, the challenge of altering an already efficient floor plan to include two new spaces is difficult. The added time and expense of the traditional closets in Mrs. Zee's Home was noticeable. The 2018-19 project house reverted back the closet zones as previous Product Line Homes have. This exploration proved inappropriate for future iterations.

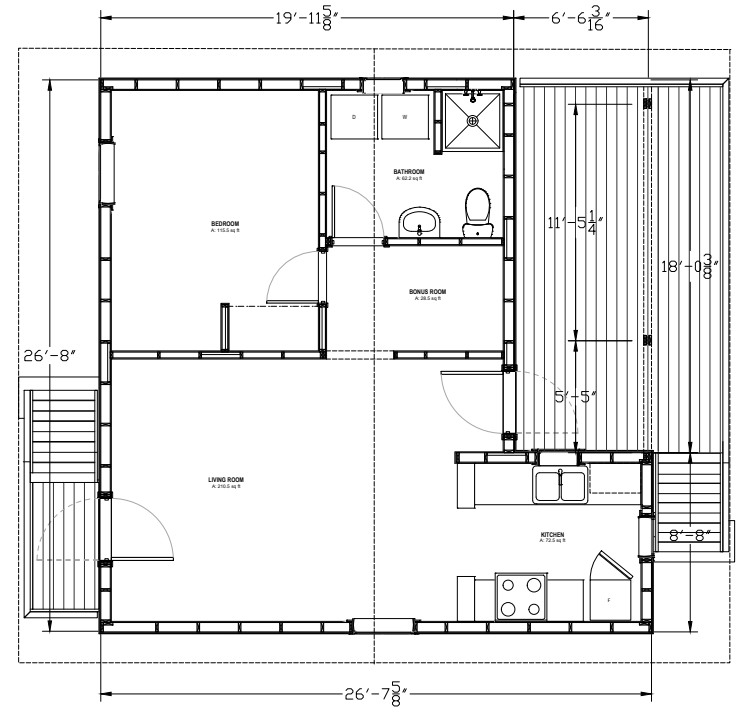

Fig 6. Mrs. Zee's new floor plan (NTS). 
Durability and energy efficiency are important to the $20 \mathrm{~K}$ House Project. The nature of a concrete slab insures it will last much longer than a plywood platform. It will be able to resist normal wear and tear and damage by leaks. It also offers the added bonus of being a thermal mass. In this climate, a thermal mass is useful in both winter and summer. Lower air infiltration rates are also a product of a slab. The solid surface prevents air passage through the floor, a difficult part of the enclosure to air seal and insulate. No quantitative data on how well this system works over the baseline system. Blower door tests can be preformed in the future and assessed for performance.

Another adjustment to Mrs. Zee's iteration is the creation of a flexible entry space. Incorporated into an earlier two-bedroom model, Version 21, the noted success proved worth using again in Mrs. Zee's Home. Moved to the bathroom, the space for both washer and dryer were reallocated to the entry of the house. Mrs. Zee uses this space for a small daybed. An additional window provides daylight in this space and a way to peek out to the front porch.

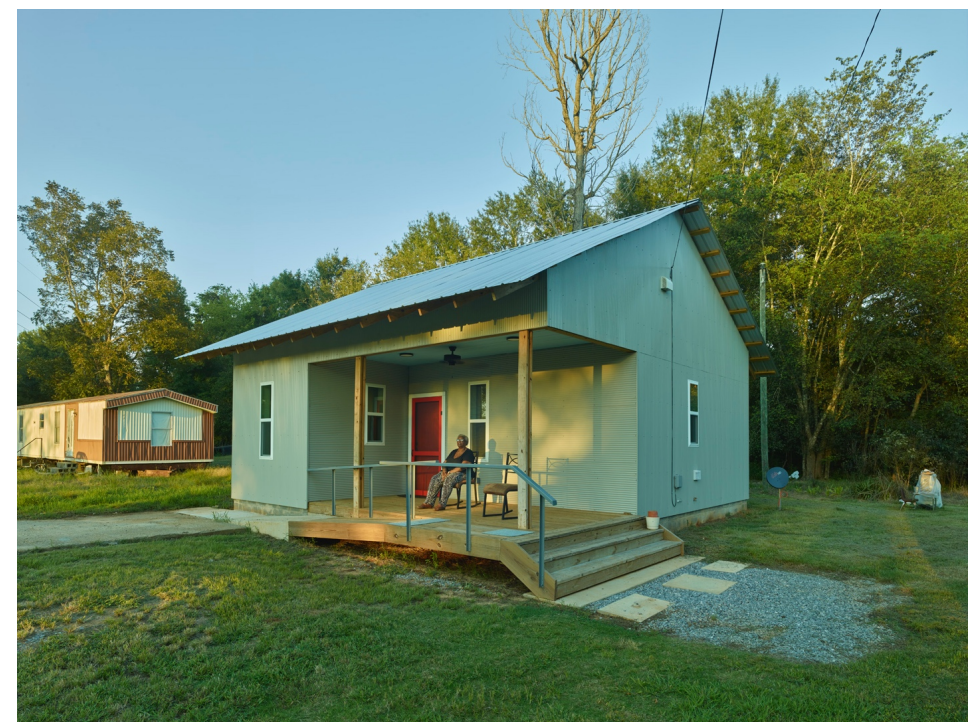

Fig 6. Mrs. Zee Home. Photo by Timothy Hursley

\section{Construction Process}

Working efficiently as a group is critical to finishing the house by the end of the academic year. Project management is a group activity for the students. There are four teams of students each semester. The teams vary from the fall to the spring. Fall teams include: Foundation and Platform, Wall Framing, Roof Framing, and Enclosure. The goal is always to be "dried-in" by the winter break.

Spring groups include: Rough Carpentry, Enclosure, MEP, and Interiors. Students in these groups become experts in these subjects and handle everything from procuring estimates to managing work onsite. Faculty oversee each aspect and work with students to teach them how to manage the budget, adjust the schedule, acquire material, and develop necessary details. Student expertise groups present to their classmates and faculty for feedback before making decisions about the direction of their work. Major decisions are always made as a group and client feedback is sought at important aspects of lifestyle choice.

\section{Moving Forward}

Another house is underway for the 2018-19 academic year. New variables are being tested such as engineered lumber products, accessibility clearances in the bathroom, and strategies for encouraging growth without disturbing passive ventilation. Mrs. Zee is happily living in her home and calls in to report feedback on what does not work from time to time. Clients receive their house as a gift from the Studio, and it comes with a one-year warranty on construction. Post occupancy evaluations will be performed in 
the future that formalizes the client's feelings of comfort (or discomfort) and documents building performance. In the future, a strategic approach to identifying quantitative characteristics of the baseline could be taken. An energy model of the selected house would provide data on the difference in performance for new details.

\section{Conclusions}

In its third year in this form, the third-year studio model was a success in the 2017-18 academic year. Ideas for what these students may study are continuously surfacing which promises a rich future for the program. The design of a design-build studio is a process. Creating opportunity for students to engage in meaningful investigations that result in successful teaching opportunities is a challenge. The Home Project is a unique program that allows iterative design-build projects to contribute to meaningful applied-research. As the program develops, third-year architecture students at the Studio will continue to participate by critically studying what exists to improve what will be built. 